\title{
AFRL-PR-WP-TR-1999-2100 \\ CONTROL OF FLOW SEPARATION \\ ON A TURBINE BLADE BY \\ UTILIZING TAIL EXTENSION
}

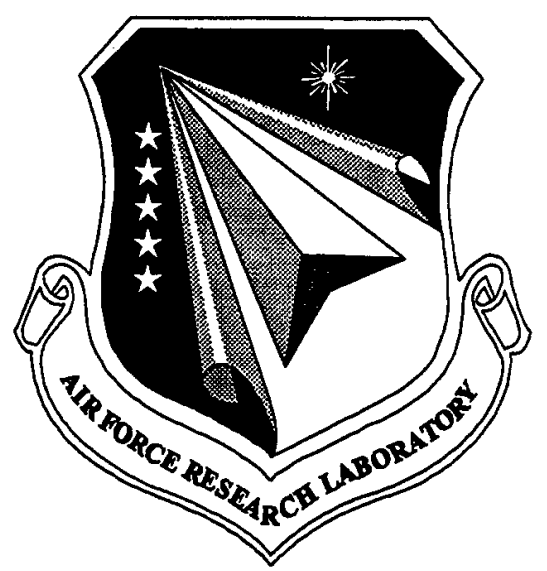

C. G. Murawski

Turbine Branch

Turbine Engine Division

Propulsion Directorate

Air Force Research Laboratory

Wright-Patterson AFB, Ohio 45433-7251

SEPTEMBER 1999

FINAL REPORT FOR PERIOD 4 SEPTEMBER 1997 - 15 MARCH 1999

Approved for public release; distribution unlimited

PROPULSION DIRECTORATE

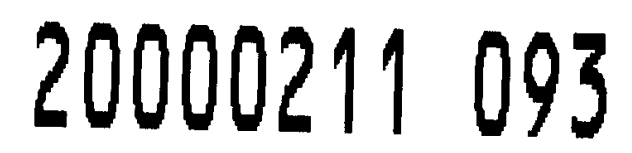

AIR FORCE RESEARCH LABORATORY

AIR FORCE MATERIEL COMMAND

WRIGHT-PATTERSON AIR FORCE BASE, OH 45433-7251 


\section{NOTICE}

USING GOVERNMENT DRAWINGS, SPECIFICATIONS, OR OTHER DATA INCLUDED IN THIS DOCUMENT FOR ANY PURPOSE OTHER THAN GOVERNMENT PROCUREMENT DOES NOT IN ANY WAY OBLIGATE THE US GOVERNMENT. THE FACT THAT THE GOVERNMENT FORMULATED OR SUPPLIED THE DRAWINGS, SPECIFICATIONS, OR OTHER DATA DOES NOT LICENSE THE HOLDER OR ANY OTHER PERSON OR CORPORATION; OR CONVEY ANY RIGHTS OR PERMISSION TO MANUFACTURE, USE, OR SELL ANY PATENTED INVENTION THAT MAY RELATE TO THEM.

THIS REPORT IS RELEASABLE TO THE NATIONAL TECHNICAL INFORMATION SERVICE (NTIS). AT NTIS, IT WILL BE AVAILABLE TO THE GENERAL PUBLIC, INCLUDING FOREIGN NATIONS.

THIS TECHNICAL REPORT HAS BEEN REVIEWED AND IS APPROVED FOR PUBLICATION.
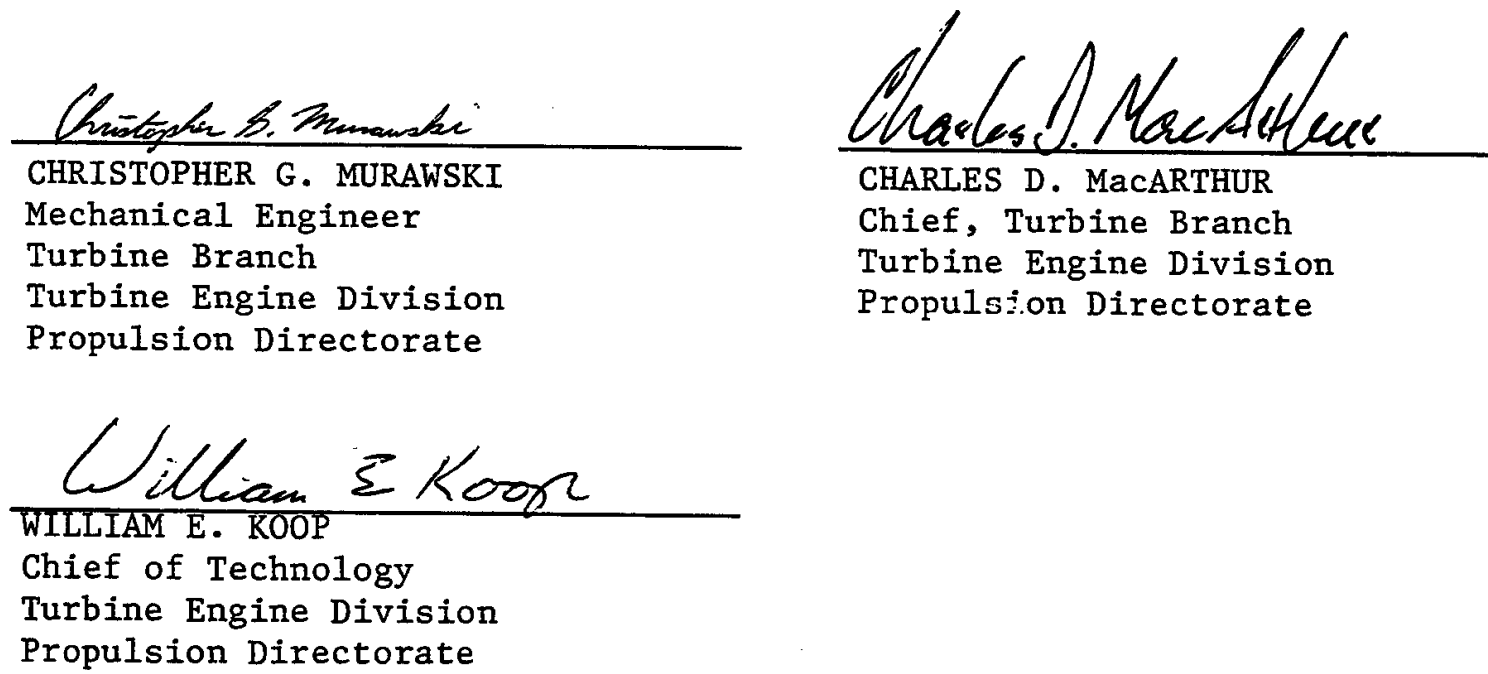

Do not return copies of this report unless contractual obligations or notice on a specific document requires its return. 


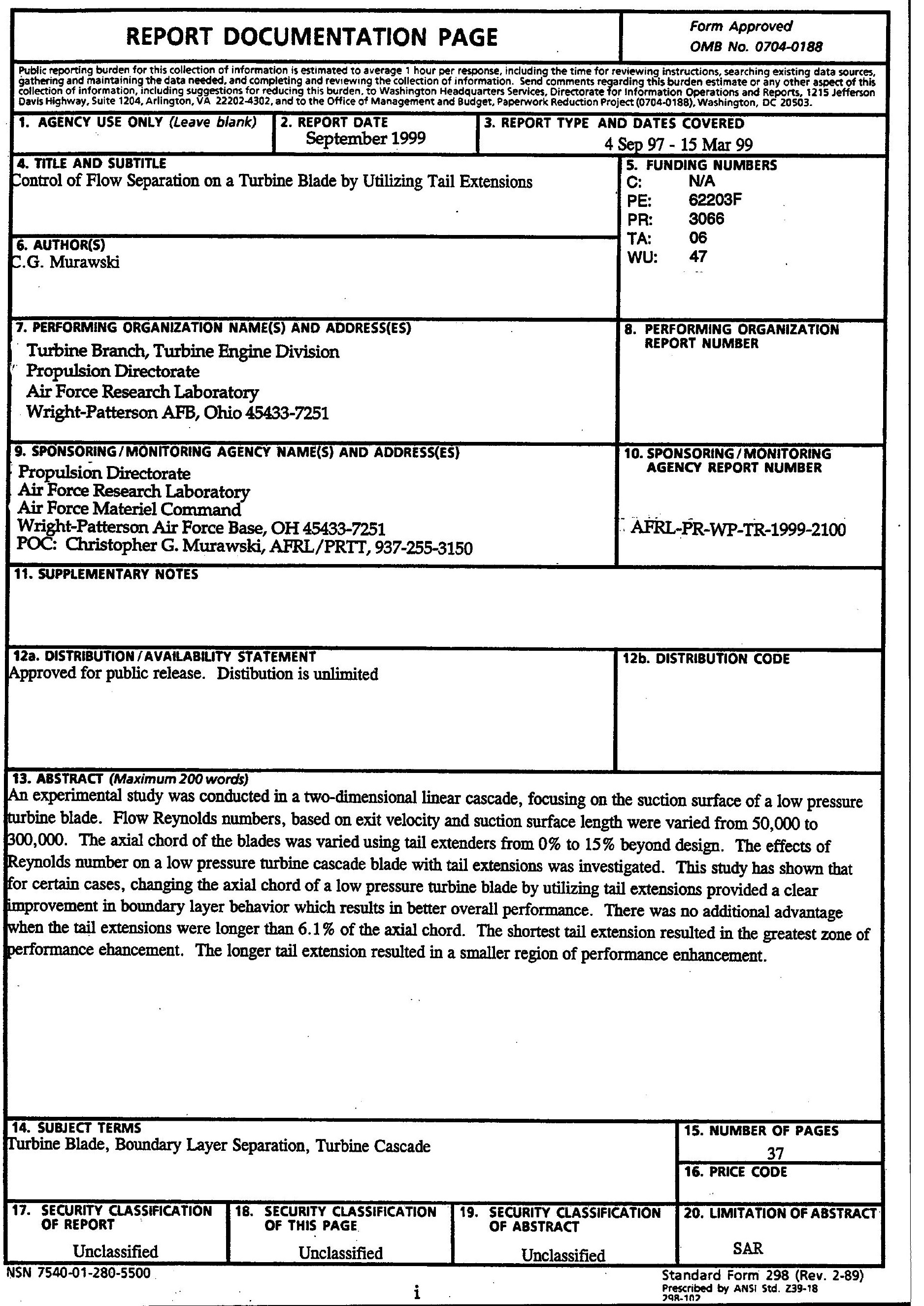




\title{
CONTROL OF FLOW SEPARATION \\ ON A TURBINE BLADE \\ BY UTILIZING TAIL EXTENSIONS
}

\author{
C. G. Murawski* \\ Propulsion Directorate, \\ Air Force Research Laboratory, USAF \\ Wright Patterson AFB, OH. 45433-7251
}

\begin{abstract}
An experimental study was conducted in a two-dimensional linear cascade, focusing on the suction surface of a low pressure turbine blade. Flow Reynolds numbers, based on exit velocity and suction surface length were varied from 50,000 to 300,000 . The axial chord of the blades was varied using tail extenders from $0 \%$ to $15 \%$ beyond design. The effects of Reynolds number on a low pressure turbine cascade blade with tail extensions was investigated. Separation was observed at all Reynolds numbers, and in all flow cases. This study has shown that for certain cases, changing the axial cord of a low pressure turbine blade by utilizing tail extensions provided a clear improvement in boundary layer behavior which results in better overall blade performance. The most profound effect of the tail extensions was seen when the tail was short. There was no additional advantage when the tail extensions were longer than $6.1 \%$ of the axial chord. The shortest tail extension resulted in the greatest zone of performance enhancement. The longer tail extension resulted in a smaller region of performance enhancement.
\end{abstract}

\footnotetext{
* Mechanical Engineer, AFRL/PRTT, Bldg 18, 1950 Fifth Street, WPAFB, OH 45433-7251
} 


\section{NOMENCLATURE}

$C p=$ Local pressure coefficient $\left(\frac{\left(P_{T_{\mathrm{in}}}-P_{S i}\right)}{\frac{1}{2} \rho U_{o u \pi^{2}}}\right)$

$P_{S i}=$ Static pressure along the blade surface

$P_{T_{i n}}=$ Total pressure at inlet of the blade set

$\overline{P_{\text {out }}}=$ Average total pressure behind the blade row

$P_{\text {Tou }, l}=$ Local total pressure behind the blade row

$\operatorname{Re}=$ Reynolds number $\left(U_{\text {our }}(\mathrm{SSL}) / v\right)$

SSL $=$ Suction surface length

$\mathrm{Tu}=$ Freestream turbulence intensity ( $\left.\mathrm{u}^{\prime}{ }^{\prime r m s} / \overline{\mathrm{u}}_{\text {local }}\right)$

$U_{o u r}=$ Average velocity out of the blade set

$\mathrm{u}^{\prime} \mathrm{ms}=$ Root mean square of fluctuating component of streamwise velocity

$\overline{\mathrm{u}}_{\mathrm{local}}=$ Local mean streamwise velocity

$\gamma=$ Loss coefficient

$v=$ Kinematic viscosity

$\rho=$ Density 


\section{BACKGROUND}

In aircraft gas turbine engines, low pressure turbine blade performance changes as the aircraft operates from takeoff to cruise. The low pressure turbine experiences large changes in chord Reynolds number because of reduced pressures while maintaining relatively high temperatures during high altitude cruise conditions. A performance degradation is caused by the decrease in the flow Reynolds numbers as the aircraft operates at high altitude cruise conditions. As Reynolds number drops, flow separation zones expand and regions of transitional flow lengthen. The end result is a degradation in performance (Sharma et al.1). The changes in Reynolds number, strong acceleration of the flow on the blade and large regions of uncovered diffusion can result in unsteady separation and transition zones on the surface of the blade.

Mayle', in a review of the role of laminar to turbulent transition in gas turbine engines, defined three modes of transition; natural transition, bypass transition and separated-flow transition. Natural transition is defined by the classical development and break-up of Tollmien-Schlichting waves. Bypass transition skips over the formation of Tollmien-Shlichting linear instability waves advancing directly to turbulent spots which eventually merge to yield a turbulent boundary layer. Separated-flow transition occurs when a boundary layer separates, and transition proceeds in the free-shear-layer flow above the 
separation bubble. The transition region propagates toward the wall giving a growing turbulent zone until the flow reattaches as a fully turbulent boundary layer. Because of the elevated levels of freestream turbulence, curvature, and the diffusion in the boundary layer, the transition processes most likely to occur on a turbine blade are bypass and separated-flow transition.

Halstead et al. ${ }^{3}$ reported the results of an extensive experimental study of compressor and low pressure turbine flows. While their experiment concentrated on turbine flow that contained wake disturbances, they concluded that the performance of highly loaded, low pressure turbine blades are dependent on flow transition and separation behavior. Murawski et al. ${ }^{4}$ reported the results of an experimental study using the two-dimensional cascade. Their low pressure turbine blade was susceptible to large regions of separation as the Reynolds number was reduced. Decreases in Reynolds number resulted in an earlier point of separation and larger separation zones. It was also shown that all the separation behavior occurs in the uncovered turning region of the suction side of the airfoil.

Rivir, et al. ${ }^{5}$ conducted a computational study of the Langston turbine cascade at Reynolds numbers relevant to low pressure turbines. Their results show that the flow over the suction side of the Langston profile separates as Reynolds number decreases below 100,000 . They extended the tail of their computational blade, thus decreasing the region of uncovered turning. This change in blade shape resulted in a significant decrease in the size of the 
separation region. The reattachment point moved forward resulting in a substantially smaller separation zone and wake width.

In the present work, the effects of changing Reynolds number on a low pressure turbine airfoil with variable axial chord are investigated. The effect of varying the axial chord by utilizing tail extensions are documented by investigating the suction side pressure profile, boundary layer surveys and the loss coefficient variations at different Reynolds numbers.

\section{EXPERIMENTAL METHOD}

\section{Experimental Apparatus}

A linear, 2-D airfoil cascade was employed to study a low pressure turbine airfoil. A schematic of the test apparatus is provided in Figure 1. Air is pulled through the apparatus by a $20 \mathrm{HP}$ motor operating a centrifugal blower in the suction mode. Air flow through the test rig is controlled by a variable speed motor controller. The wind tunnel inlet bell-mouth directs the flow through a 53 $\mathrm{cm}$ square by $20 \mathrm{~cm}$ deep honeycomb flow straightener. The flow continues through a 7:1 converging nozzle to the $11.4 \mathrm{~cm}$ by $40.6 \mathrm{~cm}$ flow channel.

The cascade used in this experiment is illustrated in Figure 2. It contains four geometrically identical, low pressure turbine blades with an axial chord length of $10.36 \mathrm{~cm}$ and a span-to-chord length aspect ratio of 1.1 . The suction surface length is $15.24 \mathrm{~cm}$. The pitch-to-chord ratio (solidity) is 0.88 and the'flow is turned through $95^{\circ}$. The freestream turbulence in this experiment was not increased beyond normal tunnel turbulence. Inlet surveys are accomplished by 
inserting instrumentation probes in slot located 1.5 axial blade chords upstream of the leading edge of the test blades. Boundary layer and downstream flow measurements were accomplished by inserting a survey cartridge in the top wall. The survey cartridge contains a slot to enable the instrumentation probe to be traversed at the required location. Different survey cartridges may be utilized for each survey.

The cascade used in this experiment has an aspect ratio (blade height-toblade pitch ratio) close to one. Secondary flow is expected near the endwalls. To establish that the secondary flow is not adversely influencing the two dimensional flow region on the blade surfaces, the boundary layer and static pressure behavior of this cascade were compared with reported experimental results of Lake et al ${ }^{6}$ and Qiu and Simon 7 . Their turbine cascades contained the same blade geometry utilized in this paper, with aspect ratios greater than five. The results of the present effort compared very favorably with the large aspect ratio cascades. The similar size and location of the separation bubble on the suction side of the turbine blade, and it's identical reaction to increasing Reynolds numbers clearly established that the cascade used in the present study contains a large enough two dimensional region which is not significantly influenced by secondary flows.

The axial chord of the blades in the linear cascade was varied by attaching a length of $1.7 \mathrm{~mm}$ thick Phenolic board to the tail at the design exit angle. The lengths of the tail attachments used in this experimental study are given in Table 
1. These tail attachments were attached to blades 2 and 3 . The axial chord was extended from $6.1 \%$ to $15.3 \%$ by using these tail attachments. It should be noted that tailboards (not tail attachments) were added to blade 1 and 4 for directing the flow across the test section as shown in Figure 2.

\section{Instrumentation}

Instantaneous local velocities were measured using a single element hotwire probe. Boundary layer profiles were recorded by traversing the single element hot-wire probe, at a 20 degree angle to the surface, across the boundary layer. The wall is located using electrical continuity between the hot-wire probe tip and the wall. The distance from the hot-wire to the wall was calculated and corrected by measuring the tip diameter of the probe. Boundary layer profiles were measured on a cascade blade at position 2 as illustrated in Figure 2. The percent axial chord locations at which the traverses were recorded are annotated on blade 2 .

Mean inlet velocity and total pressure measurements were made with a pitot-static probe. The airfoil surface static pressures are measured using 22 static pressure ports installed at midspan on the surface of one blade. The surface static pressure test blade was inserted in blade position 2 in the test section. The locations of the surface static pressure taps on the test blade are illustrated in Figure 3. One pressure tap is located near the front stagnation point, nine surface pressure taps are located on the pressure side of the test blade and 12 static pressure taps are located in the suction side of the test blade. It 
should be noted that the numbers cited on the blade in Figure 3 refer to the percent axial chord. The ports are connected to stainless steel tubing which manifolds to a Scanivalve selector. Three different Validyne pressure transducers were used to cover the range of cascade pressures. Voltages were acquired using a National Instruments Data Acquisition Board. National Instruments LabVIEW software was utilized for data acquisition.

The experimental uncertainties were determined based on the method of Kline and $\mathrm{McClintock}^{8}$. The uncertainty of the velocity measurements resulting from pressure transducers was calculated to be less than $2 \%$. The maximum uncertainty in the pressure coefficient and loss coefficient were calculated to be less than $4 \%$. The uncertainty of the velocity measurements from single wire, hot wire anemometer was calculated to be less than $2 \%$.

\section{RESULTS}

\section{$\underline{\text { Inlet Velocity Profile }}$}

To verify an acceptable inlet flow, a velocity survey was performed using a single hot-wire probe. The survey was taken two blade chords upstream of the leading edges of the cascade blades at mid-tunnel height. The maximum variation from the mean inlet velocity for Reynolds number of 50,000, 100,000 and 200,000 was $3.57 \%, 3.38 \%$ and $3.65 \%$ respectively. The inlet freestream turbulence intensity for the Reynolds numbers as listed above was $0.61 \%, 0.54 \%$ and $1.08 \%$ respectively. 


\section{Surface Static Pressure Surveys}

Surface static pressure surveys were conducted on the 2-D cascade test blade for a wide range of Reynolds numbers. The results are presented in terms of a pressure coefficient defined by

$$
C p=\frac{\left(P_{x_{\text {in }}}-P_{S i}\right)}{\frac{1}{2} \rho U_{o u r^{2}}}
$$

where $P_{T_{i n}}$ is the total pressure at the inlet of the blade set, $P_{s i}$ is the static pressure along the blade surface, and $U_{\text {our }}$ is the average velocity out of the blade set. The method used to interpret the separation region on static pressure coefficient plots over the pertinent portion of the suction side is illustrated in

Figure 4. This method is similar to that employed by Gaster'. A region of the pressure plot that contains a flat zone or terrace is an indication of separated flow. The terrace is created by the initial portion of the separation bubble composed of a laminar shear layer and a dead air region. The magnitude of the velocity near the wall remains low as the shear layer interacts with the separation bubble. This mixing may result in boundary layer reattachment. Toward the end of the separation bubble the magnitude of the velocity will increase near the wall. Mayle ${ }^{2}$ defined the end of transition as the knee on the static pressure curve that begins to quickly fall off after the flat zone. Although the exact location of reattachment is not determined using this criteria, the boundary layers for each flow case can be compared by recording the beginning of the separation terrace and the beginning of the pressure recovery (the knee on the 
static pressure curve) in the static pressure plots. These observations are summarized in Table 2 . It should be noted that Table 2 contains results from the surface static pressure surveys (location of maximum velocity, terrace beginning and end location, and terrace length) and the boundary layer hot-wire traverses (separation and reattachment).

Figure 5 illustrates the surface static pressure survey for the cascade without tail extensions with varying Reynolds numbers. The pressure side is the lower portion of the plot. For all Reynolds numbers the flow is attached for the whole length of the pressure side. The suction side is the top portion of the Figure 5. The results show a separation occurring near 74 percent axial chord for Reynolds numbers less than 100,000 . The point of separation moves forward as Reynolds number is increased beyond 100,000. The location of the initiation of separation is effected for different values of Reynolds numbers. The location of the end of the static pressure terrace, which is interpreted as the end of transition, also changes with Reynolds number. The terrace ends at about 85 percent axial chord for Reynolds number of 50,000. As Reynolds number is increased, the end of transition point moves forward. At a Reynolds number of 300,000 , the flat terrace ends near 74 percent axial chord.

Figure 6 illustrates the results of the surface static pressure surveys for the suction side of the airfoil. Each plot contains the results of one Reynolds number, and the effect of varying the axial chord. Figure 6a illustrates the results of the suction side surface static pressure survey for Reynolds number of 50,000. The 
solid line represents the baseline blade with no tail extension. Adding a relatively short tail extension to the baseline blade delays the location of maximum velocity on the suction surface delays the onset of separation and decreases the separation zone size. The terrace length is decreased by 18 percent. Increasing the tail length for the case of Reynolds number of 50,000 does not change the terrace length any further. For this case, a short tail extension of about $6 \%$ will be adequate to provide the largest impact on the boundary layer.

Figures $6 \mathrm{~b}$ and $6 \mathrm{c}$ illustrates the results of the suction side surface static pressure surveys for Reynolds number of 100,000 and 200,000 respectively. The summary of results in Table 2 shows that the suction side surface behaves similarly for this range of Reynolds number. The terrace length shrinks substantially as compared to the case when no tail is attached. Separation moves rearward when a tail extension is attached to the baseline blade. Increasing the tail length does not have much of an impact on the point of separation. The terrace lengths on the static pressure survey plots remain constant for tail lengths of $1.27 \mathrm{~cm}, 1.90 \mathrm{~cm}$ and $2.54 \mathrm{~cm}$.

The largest impact of the tail extensions was recorded for Reynolds number of 100,000 . Table 2 shows that for Reynolds number of 100,000 , the short tail extension of 1.27 delays boundary layer separation and decreases the terrace length by more than $75 \%$. As the tail extension is increased beyond $2.54 \mathrm{~cm}$ the terrace length, which corresponds to separation zone size, remains constant at less than half the length of the no tail extension case. 
The results in Table 2 show that as the Reynolds number increases from 100,000 to 200,000 for the baseline case, without tail extension, the separation zone is similar in size as the whole separation bubble moves forward on the suction side blade surface. When the shorter tail extensions are added to the blade, at Reynolds number of 200,000 , the terrace length on the static pressure survey shrinks by about half. However, when the tail extension was increased to $3.17 \mathrm{~cm}$, the size of the terrace increases almost back to the baseline length. This occurs even though the location of separation, point at which the terrace begins, was moved downstream from $68 \%$ axial chord to $74 \%$ axial chord. The advantage gained by tail attachments is constant after exceeding a certain attachment length as seen in Figures $6 \mathrm{c}$ and Table 2. This gives an indication for the existence of an optimized tail length for a given range of Reynolds numbers. For the low pressure turbine blade utilized in the present investigation the greatest impact on the suction side boundary layer was seen when the tail extension lengths were about $6 \%$ of axial chord.

Figure 6d illustrates the results of the suction side surface static pressure survey for Reynolds number of 300,000 . In this case the tail attachments have the effect of delaying the point of maximum velocity, and the onset of separation. The length of the terrace, which is an indication of the length of separation, is hardly influenced by the tail attachments. Table 2 shows the terrace length growing by 1 percent axial chord when tails are attached. This change in terrace 
length is not significant. This indicates that the impact of the tail attachments is diminished for larger Reynolds numbers.

Boundary Layer Survey

Boundary layer profiles were obtained for the baseline (no tail extension), $1.27 \mathrm{~cm}$ and $1.90 \mathrm{~cm}$ tail attachment cases for Reynolds numbers of 50,000, 100,000 and 200,000 . The static pressure surveys established that the greatest performance enhancement was when tail attachments of $9.2 \%$ of the axial chord or less were utilized. The static pressure surveys were able to show the point of separation and end of the transition on the suction side boundary layer. The suction side boundary layer reattachment point could not be determined accurately from the surface static pressure surveys. To determine the reattachment point a boundary layer survey was conducted. The results of the boundary layer survey are summarized in Table 2 . Detailed velocity profiles and local turbulence intensities were recorded within the boundary layer. Interpretation of the boundary layer surveys was similar to that used by Murawski et al.4 and Qiu and Simon?.

Figure 7 shows the results of the boundary layer velocity survey for the three tail configurations with Reynolds number of 50,000. Separation occurs for the baseline, no tail, case at about $74 \%$ axial chord. Separation of the boundary layer is delayed when tail extensions are added. Figure 8 shows the local turbulence intensity distribution within the boundary layer for different tail extensions. Laminar attached flow is a region in which the local turbulence 
intensity remains below $10 \%$. Separated flow appears as a turbulence intensity curve in which the peak turbulence intensity is not at the wall, but occurs in the shear layer on top of the separation bubble. Attached turbulent boundary layer appears as a curve where the maximum turbulence intensity occurs near the wall and values of turbulence intensity decrease away from the wall. For all cases, the boundary layer is attached at $68 \%$ axial chord. At $74 \%$ axial chord, the boundary has separated for the no tail case, while the boundary layer remained attached for the $1.27 \mathrm{~cm}$ and $1.90 \mathrm{~cm}$ tail extension cases. At $81 \%$ axial chord all the boundary layers in Figures 7 and 8 are separated whereas the baseline case has been separated before the $74 \%$ axial chord. The separation region can be seen as the chord section over which zero velocity gradient at the wall exists, appears as a large low velocity region on the velocity profiles.

It appears at first, that the $1.90 \mathrm{~cm}$ tail results in a better behaved boundary layer by delaying the separation point. However at $96 \%$ axial chord, while the velocity profiles (Figure 7) appear very similar, the boundary layer turbulence intensity (Figure 8) reveals the actual state of the boundary layer. For the baseline case, at $96 \%$ axial chord, the flow has either just attached or is about to attach as a turbulent boundary layer. For the $1.27 \mathrm{~cm}$ tail case, the flow is clearly attached because the local turbulence intensity is highest at the wall and falls away quickly as distance from the wall is increased. For the $1.90 \mathrm{~cm}$ case, at the $96 \%$ axial chord, the boundary layer is not yet attached, but attachment will occur soon because the high turbulence intensity has diffused toward the wall. 
For a Reynolds number of 50,000, it can be concluded that increasing the axial chord by $6.1 \%$, using a tail attachment, results in a delayed and smaller separation region. The $1.90 \mathrm{~cm}$ tail delays the separation further downstream compared to the $1.27 \mathrm{~cm}$ tail, however the shorter tail results in a shorter separation zone.

Figures 9 and 10 respectively illustrate the velocity and freestream turbulence distributions for a Reynolds number of 100,000. For the baseline case, i.e., no tail extension, the flow has separated at $74 \%$ axial chord, and has reattached at $96 \%$ axial chord. For the $1.27 \mathrm{~cm}$ and $1.90 \mathrm{~cm}$ tail extensions the boundary layer separation is delayed until before $81 \%$ axial chord, and the reattachment occurs before the $96 \%$ axial chord marker. For Reynolds number of 100,000 , it can be seen that using the shorter $1.27 \mathrm{~cm}$ tail is adequate (Table 2) in providing a meaningful performance enhancement on the low pressure turbine airfoil. Using a longer tail extension will not provide a greater performance enhancement.

The boundary layer surveys for Reynolds number of 200,000 are illustrated in Figures 11 and 12. As can be seen in Figure 11 the boundary layer for the baseline case (no tail extension) separates after the $68 \%$ axial chord marker. Once again, the tail extension cases delay the separation point. In this case the separation point is delayed until after the $74 \%$ axial chord location. The similarity between the boundary layer freestream turbulence levels (Figure 12) for the baseline and tail extension cases indicates that the reattachment point is 
not effected by the addition of the tail extensions. For the baseline case as well as the tail extension attachment cases the boundary layers are attached around the $90 \%$ axial chord marker. Therefore, the use of a variable axial chord turbine blade provides only a minimal performance enhancement for Reynolds number of 200,000 .

For all Reynolds numbers, it can be seen from Figures 7, 9, and 11, based on observing the length of the flat portion of the velocity profile, that the height of the separation bubble decreases when tail extension are attached to the test blade. The height of the separation bubble decreases slightly as the tail extension increases from $6.1 \%$ to $9.2 \%$.

The flow separation on the suction side boundary layer occurs in the area of uncovered turning, or uncovered diffusion. The aft portion of the turbine blade is where the majority of flow diffusion occurs without the direct control of the pressure side wall of the opposing blade. The static pressure plots and the boundary layer results without any tail extensions shows that this is the region where the boundary layer separation behavior takes place. The addition of the tail extensions decreases the region of uncovered diffusion, which delays the onset of boundary layer separation on the suction side. Also the tail extensions decrease the height of the separation bubble. This smaller separation zone results in less blade profile drag and a decrease in the extent of shear layer mixing over the separation bubble. These factors contribute to better overall blade performance at lower Reynolds numbers. The boundary layer 
reattachment point, which remains in the uncovered turning region, is not effected by the presence of the tail extensions.

\section{$\underline{\text { Loss Coefficient }}$}

Overall performance is documented with the loss coefficient.

$$
\gamma=\frac{\left(P_{T_{\text {in }}}-\overline{P_{T_{\text {out }}}}\right)}{\frac{1}{2} \rho U_{o u \pi^{2}}}
$$

In this work, the inlet total pressure is measured two axial blade chords upstream while the outlet total pressure which is the average of a traverse perpendicular to the exit flow, is measured at $25 \%$ of axial chord downstream of the test blade. Figure 13 shows the loss coefficients for the blade set without tail attachments as well as the blade set with $1.27 \mathrm{~cm}$ and $1.90 \mathrm{~cm}$ tail attachments. Figure 13 shows that for all cases the overall blade losses decreases as Reynolds numbers increases. The $1.27 \mathrm{~cm}$ tail attachment resulted in higher loss coefficients when the Reynolds number was 300,000 . The $1.27 \mathrm{~cm}$ tail attachment results in a better performance for Reynolds numbers less than 200,000 . This is the range usually specified as the cruise condition for a low pressure turbine. Above a Reynolds number of 200,000, both the $1.7 \mathrm{~cm}$ and $1.9 \mathrm{~cm}$ tail extensions resulted in a larger loss coefficient than the base case. The $1.90 \mathrm{~cm}$ tail extension shows a performance improvement within a smaller range confined to a Reynolds number of about 100,000 . The shorter $1.27 \mathrm{~cm}$ tail returns lower loss coefficients for a Reynolds numbers range from 50,000 to around 200,000 . This is a much greater range as compared to the longer tail extension case. Loss 
coefficients were not recorded for tails longer than $1.90 \mathrm{~cm}$ because Table 2 showed that longer tail attachments resulted in no improvement in reducing the extent of the separation zone for the majority of cases.

Figure 13 shows that this low pressure turbine was designed to have optimal performance at Reynolds numbers of 300,000 or greater. The addition of tail extensions changes the blade solidity (axial chord to blade pitch ratio), and changes the region of uncovered turning. At the higher Reynolds numbers this results in higher overall losses. A large boundary layer separation is observed on the suction side of the blade, in the region of uncovered diffusion at lower Reynolds numbers. The change in blade geometry from the addition of tail extensions leads to lower overall losses at the lower Reynolds numbers.

\section{CONCLUSIONS}

In the present study, the effects of Reynolds number on a low pressure turbine cascade blade with variable axial chord was investigated. Separation was observed at all Reynolds numbers, and in all flow cases in this experimental study. It has been established that tail extensions provide a clear improvement in suction side boundary layer behavior which can result in a better blade performance. The most profound effect of the tail extensions was seen when the tail extension was relatively short. There was no additional advantage when the tail extension was longer than about $6.1 \%$ of axial chord and in fact in some cases the performance was downgraded for a longer tail extension. 
It was found that the tail extensions tend to delay the separation point on the suction side of the low pressure turbine blade. For Reynolds number less than 300,000 , the size of the separation zone is substantially affected by the presence of the tail extensions. The shortest tail extension resulted in the greatest zone of performance enhancement on the loss coefficient in the range of Reynolds number from 50,000 to 200,000 . The longer tail extensions resulted in a smaller region of performance enhancement. The tail extensions resulted in larger losses at Reynolds numbers beyond 200,000.

The addition of tail extensions changes the blade solidity (axial chord-to-blade pitch ratio), and changes the region of uncovered turning. At higher Reynolds numbers this resulted in higher overall losses. However, at lower Reynolds numbers, the addition of the tail extensions, which decreased the region of uncovered diffusion, delayed the onset of boundary layer separation on the suction side and decreased the height of the separation bubble. This smaller separation zone resulted in less blade profile drag and a decreased in the extent of shear layer mixing over the separation bubble. These factors contributed to lower losses and better overall blade performance at lower Reynolds numbers. 


\section{ACKNOWLEDGEMENTS}

The author is grateful for the professional assistance and advice from members of the Air Force Research Laboratory's Propulsion Directorate Basic Aerothermal Research Program. Guidance was also received from Professor Kambiz Vafai of the Ohio State University Department of Mechanical Engineering. The author is also grateful for the support of Dr. Paul King of the Air Force Institute of Technology (AFIT) Aeronautical Engineering Department for use of the linear cascade. The author would also like to acknowledge the help of the AFIT model shop and the University of Dayton Department of Mechanical Engineering machine shop. 


\section{REFERENCES}

1) Sharma, O.P., Ni, R.H., and Tanrikut, S., "Unsteady Flows in Turbines - Impact on Design Procedure," AGARD-LS-195, Paper No. 5, 1994.

2) Mayle, R.E., "The Role of Laminar-Turbulent Transition in Gas Turbine Engines," ASME Paper No. 91-GT-282, 1991.

3) Halstead, D.E., Wisler, D.C., Okiishi, T.H., Walker, G.J., Hodson, H.P., and Shin, H-W., "Boundary Layer Development in Axial Compressors and Turbines Part 4 of 4: Computations and Analysis," ASME paper No. 95-GT-464, 1995.

4) Murawski, C.G., Sondergaard, R., Rivir, R.B., Vafai, K., Simon, T.W., and Volino, R.J., "Experimental Study of the Unsteady Aerodynamics in a Linear Cascade with Low Reynolds Number Low Pressure Turbine Blades," ASME paper No. 97-GT-95, 1997.

5) Rivir, R., Sondergaard, R., Dahlstrom, M., and Ervin, E., “Low Reynolds Number Turbine Blade Cascade Calculations," ISROMAC-6, The 6th International Symposium on Transport Phenomena and Dynamics of Rotating Machinery, Honolulu, HA, Vol. II, 1996, pp 132-141.

6) Lake, J.P., King, P.I., Rivir, R.B., "Reduction of Separation Losses on a Turbine Blade with Low Reynolds Numbers," AIAA Paper No. 99-0242, 1999.

7) Qiu, S., and Simon, T.W., "An Experimental Investigation of Transition as Applied to Low Pressure Turbine Suction Surface Flows," ASME paper No. 97GT-455, 1997.

8) Kline, S.J., and McClintock, F.A., "Describing Uncertainties in Single-Sample Experiments," Mechanical Engineering," Vol. 75, 1953, pp. 3-8.

9) Gaster, M., "The structure and Behavior of Laminar Separation Bubbles," AGARD-CP-4, 1966, pp. 819-854. 


\section{List of Tables:}

Table 1. Tail Attachment Data

Table 2. The Effect of Variable Axial Chord: Suction Side Static Pressure and Boundary Layer Results

\section{List of Figures:}

Figure 1. Test Apparatus

Figure 2. Test Section

Figure 3. Surface Static Pressure Tap Locations

Figure 4. Interpretation of the Separation Region on Static Pressure Plot over the Pertinent Portion of the Suction Side

Figure 5. Static Pressure Survey, Baseline

Figure 6. Effect of Variable Axial Chord on the Static Pressure Distribution on the Suction Side for a) $\operatorname{Re}=50,000$, b) $\operatorname{Re}=100,000$, c) $\operatorname{Re}=200,000$, d) $\operatorname{Re}=300,000$

Figure 7. Velocity Distribution at Different Axial Chord Locations along the Blade Suction Side for $\operatorname{Re}=50,000$

Figure 8. Turbulence Level Distribution at Different Axial Chord Locations along the Blade Suction Side for $\operatorname{Re}=50,000$

Figure 9. Velocity Distribution at Different Axial Chord Locations along the Blade Suction Side for $\operatorname{Re}=100,000$

Figure 10. Turbulence Level Distribution at Different Axial Chord Locations along the Blade Suction Side for $\operatorname{Re}=100,000$

Figure 11. Velocity Distribution at Different Axial Chord Locations along the Blade Suction Side for $\operatorname{Re}=200,000$

Figure 12. Turbulence Level Distribution at Different Axial Chord Locations along the Blade Suction Side for $\operatorname{Re}=200,000$

Figure 13. Loss Coefficient Variations at Different Reynolds Numbers 
Table 1. Tail Attachment Data

\begin{tabular}{|c|c|c|c|c|c|}
\hline Tail Length $(\mathrm{cm})$ & 0.0 & 1.27 & 1.90 & 2.54 & 3.17 \\
\hline $\begin{array}{c}\text { Suction Side Surface } \\
\text { Length }(\mathrm{cm})\end{array}$ & 15.24 & 16.51 & 17.14 & 17.78 & 18.41 \\
\hline Axial Chord $(\mathrm{cm})$ & 10.36 & 10.99 & 11.31 & 11.63 & 11.94 \\
\hline Change in Axial Chord & Base & $+6.1 \%$ & $+9.2 \%$ & $+12.3 \%$ & $+15.3 \%$ \\
\hline
\end{tabular}


Table 2. The Effect of Variable Axial Chord: Suction Side Static Pressure and Boundary Layer Results

\begin{tabular}{|c|c|c|c|c|c|c|}
\hline $\begin{array}{c}\text { Reynolds } \\
\text { Number }\end{array}$ & $\begin{array}{c}\text { Tail } \\
\text { Length }\end{array}$ & $\begin{array}{c}\text { Maximum } \\
\text { Velocity }\end{array}$ & $\begin{array}{c}\text { Terrace } \\
\text { Begins/ } \\
\text { Separation }\end{array}$ & $\begin{array}{c}\text { Transition } \\
\text { (Terrace } \\
\text { Ends) }\end{array}$ & $\begin{array}{c}\text { Terrace } \\
\text { Length }\end{array}$ & $\begin{array}{c}\text { Reattach } \\
\text { ment }\end{array}$ \\
\hline 50,000 & No Tail & 54 & $74 /<74$ & 85 & 11 & 96 \\
\hline & $1.27 \mathrm{~cm}$ & 58 & $81 /<81$ & 90 & 9 & 96 \\
\hline & $1.90 \mathrm{~cm}$ & 58 & $81 /<81$ & 90 & 9 & $>96$ \\
\hline & $2.54 \mathrm{~cm}$ & 62 & 81 & 90 & 9 & \\
\hline & $3.17 \mathrm{~cm}$ & 62 & 81 & 90 & 9 & \\
\hline & & & & & & \\
\hline 100,000 & No Tail & 54 & $74 /<74$ & 85 & 11 & 96 \\
\hline & $1.27 \mathrm{~cm}$ & 56 & $81 /<81$ & 85 & 4 & 96 \\
\hline & $1.90 \mathrm{~cm}$ & 58 & $81 /<81$ & 85 & 4 & 96 \\
\hline & $2.54 \mathrm{~cm}$ & 58 & 81 & 85 & 4 & \\
\hline & $3.17 \mathrm{~cm}$ & 60 & 81 & 85 & 4 & \\
\hline & & & & & & \\
\hline 200,000 & No Tail & 54 & $68 />68$ & 80 & 12 & 90 \\
\hline & $1.27 \mathrm{~cm}$ & 54 & $74 />74$ & 81 & 7 & 90 \\
\hline & $1.90 \mathrm{~cm}$ & 58 & $74 />74$ & 81 & 7 & 90 \\
\hline & $2.54 \mathrm{~cm}$ & 58 & 74 & 81 & 7 & \\
\hline & $3.17 \mathrm{~cm}$ & 58 & 74 & 85 & 11 & \\
\hline & & & & & & \\
\hline 300,000 & No Tail & 54 & 68 & 74 & 6 & \\
\hline & $1.27 \mathrm{~cm}$ & 56 & 74 & 81 & 7 & \\
\hline & $1.90 \mathrm{~cm}$ & 56 & 74 & 81 & 7 & \\
\hline & $2.54 \mathrm{~cm}$ & 58 & 74 & 81 & 7 & \\
\hline & $3.17 \mathrm{~cm}$ & 58 & 74 & 81 & 7 & \\
\hline Values for & maxim & & & & & \\
\hline
\end{tabular}

(Values for maximum velocity, terrace dimensions and reattachment are given in terms of axial chord percentage.) 


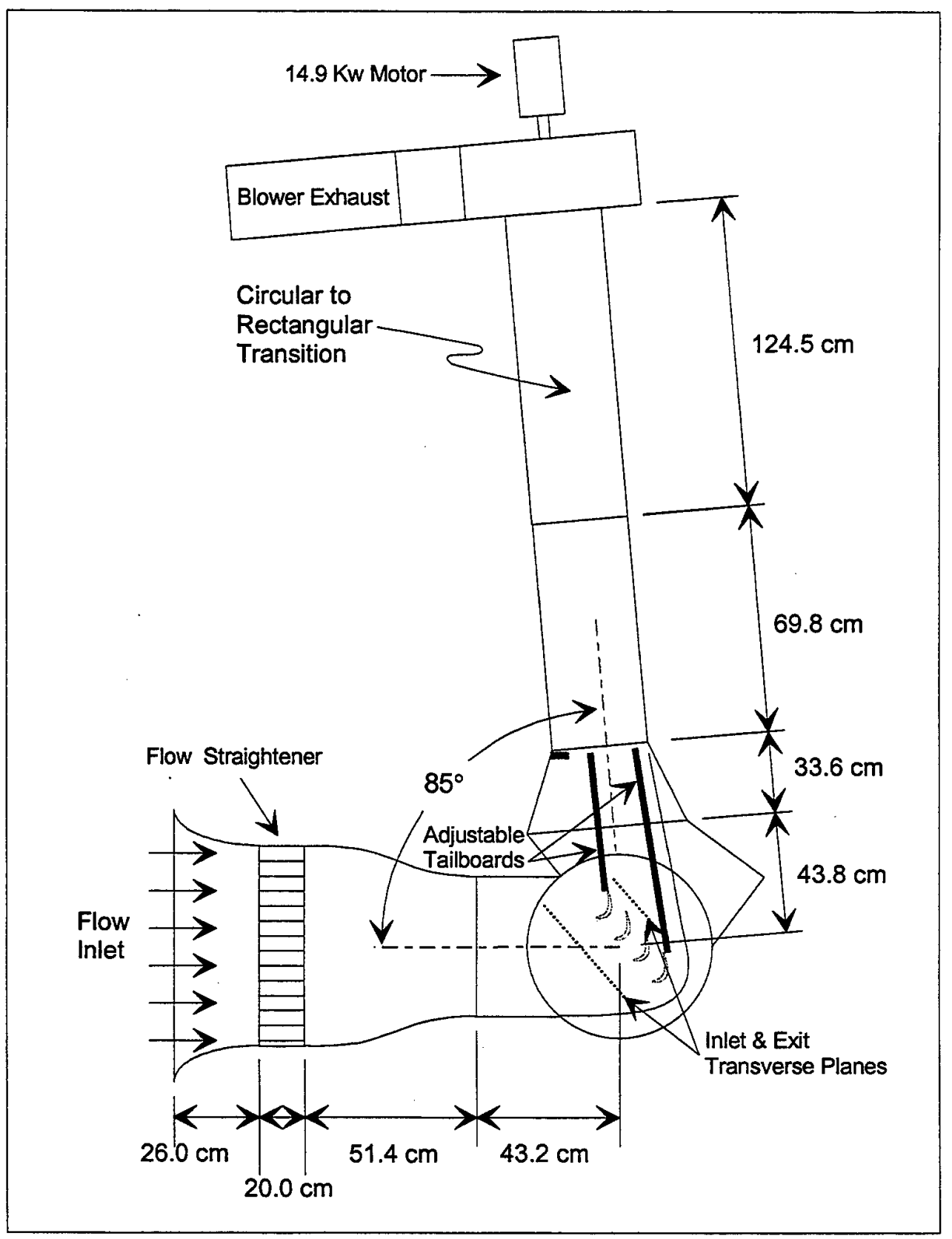

Figure 1. Test Apparatus 


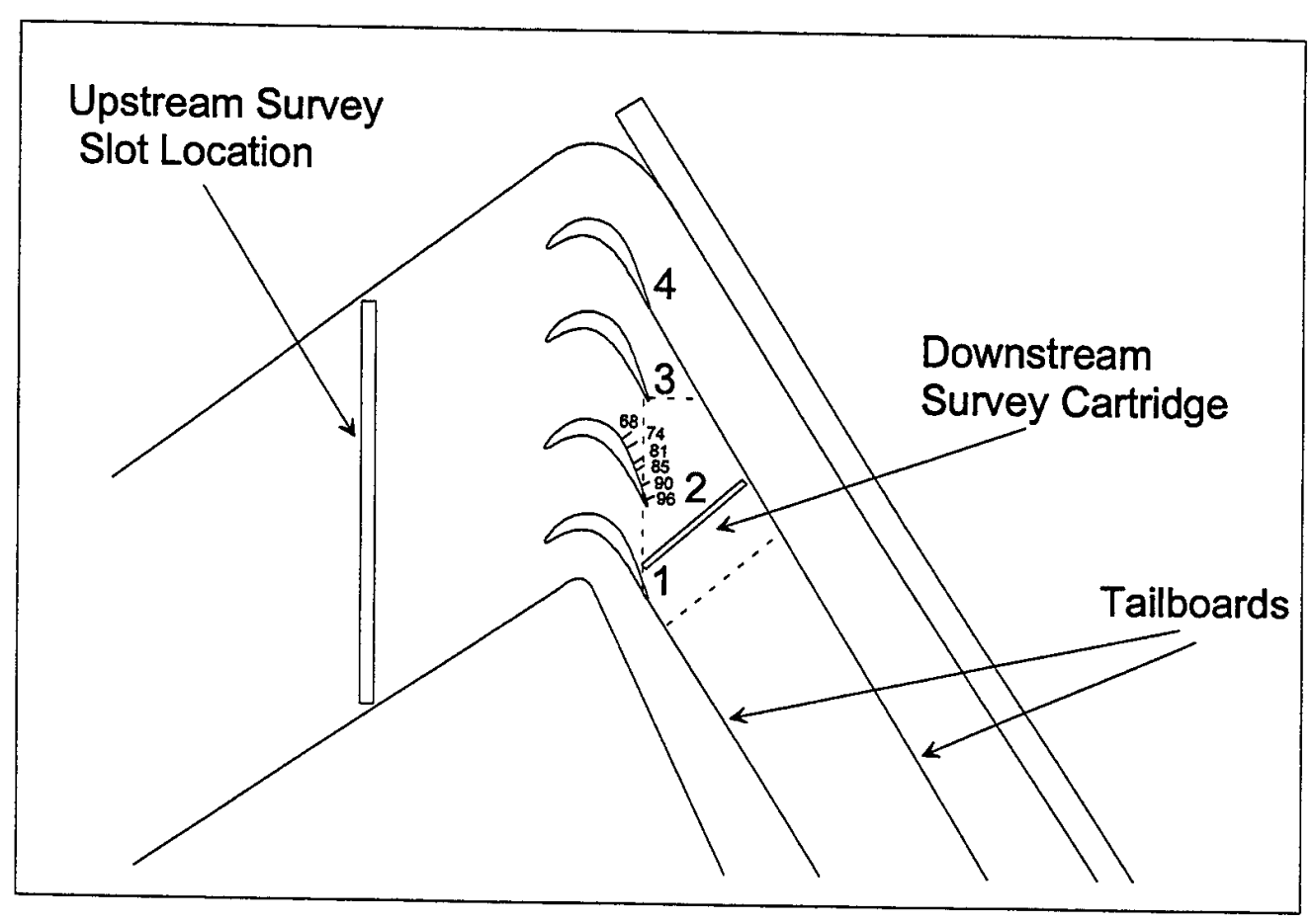

Figure 2. Test Section 


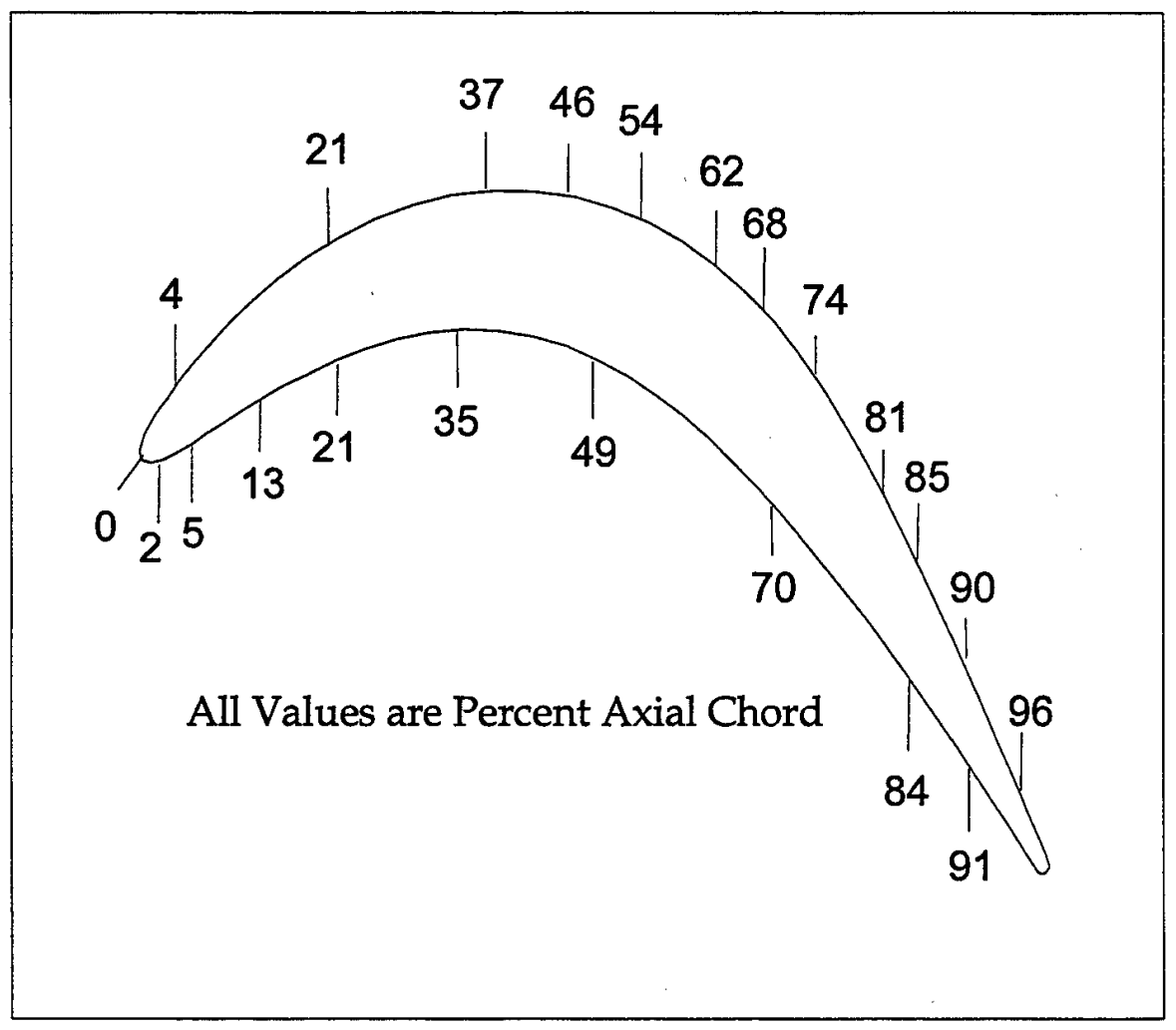

Figure 3. Surface Static Pressure Tap Locations 


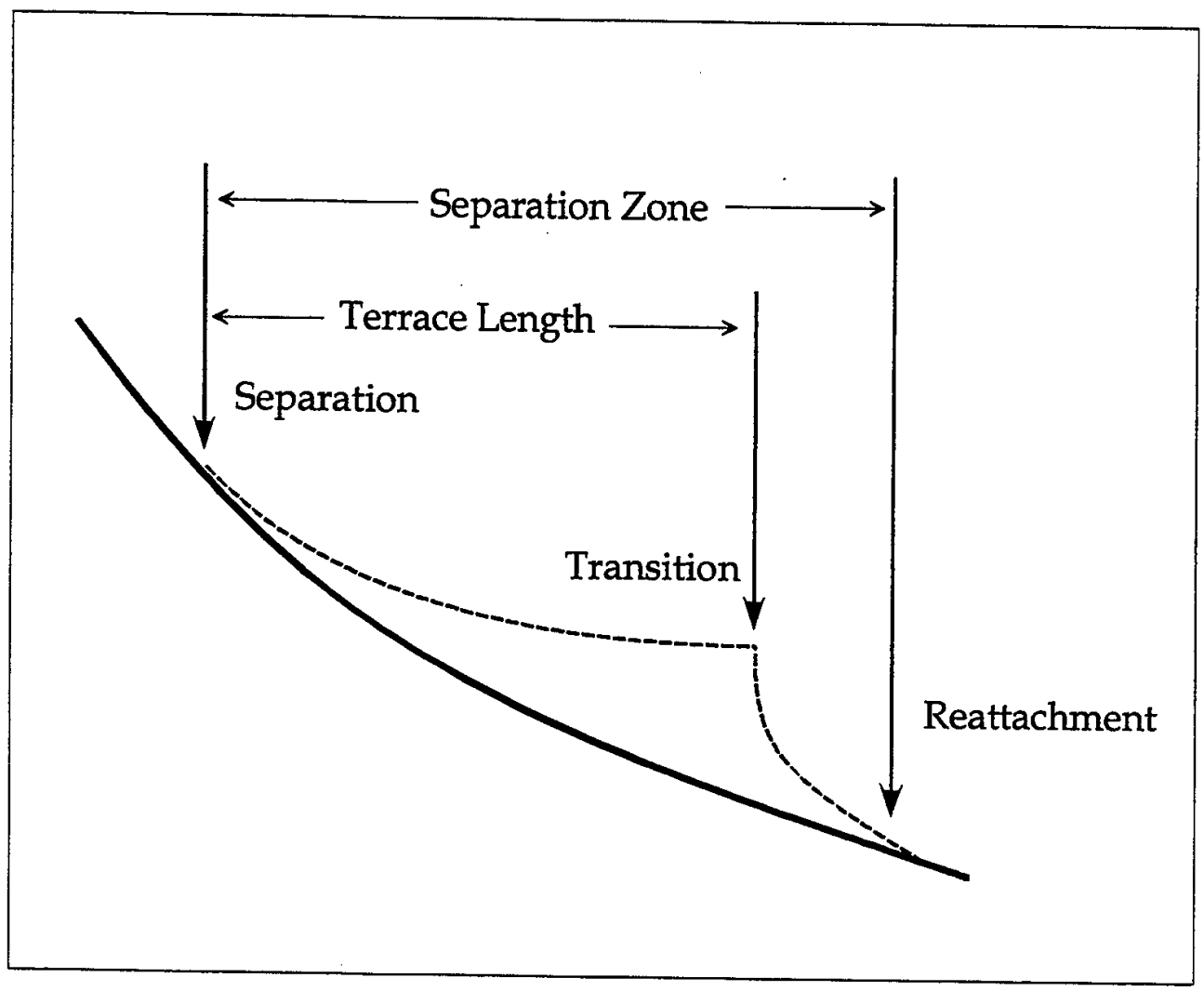

Figure 4. Interpretation of the Separation Region on Static Pressure Plot over the Pertinent Portion of the Suction Side 


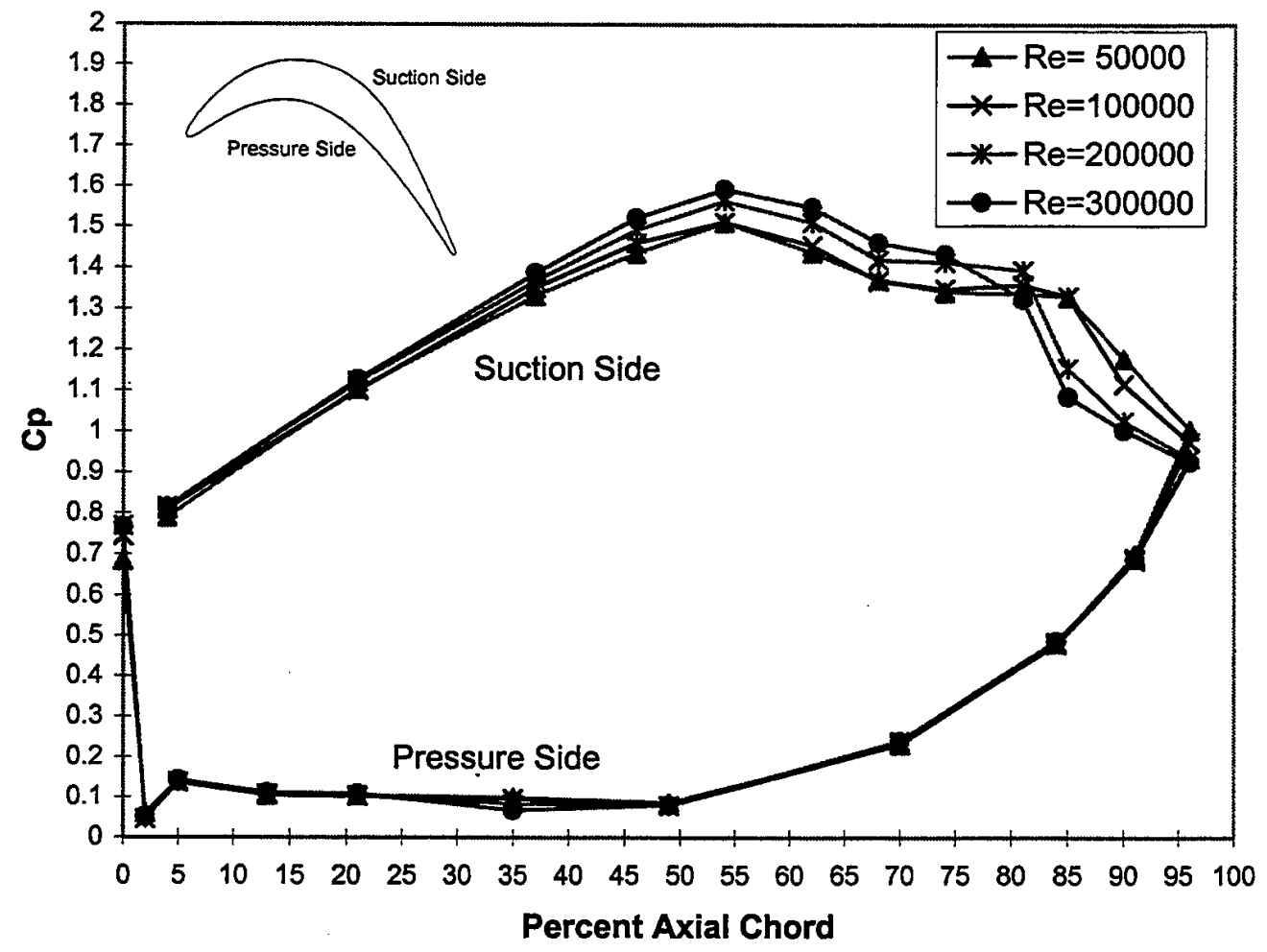

Figure 5. Static Pressure Survey, Baseline 


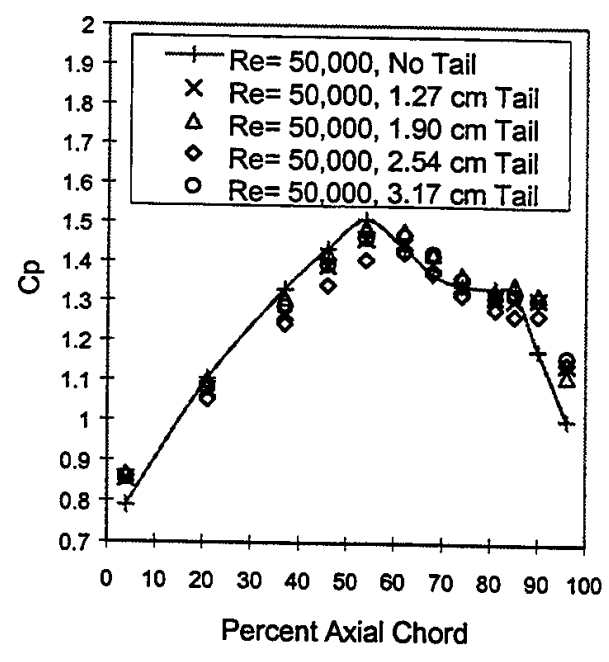

a) $\operatorname{Re}=50,000$

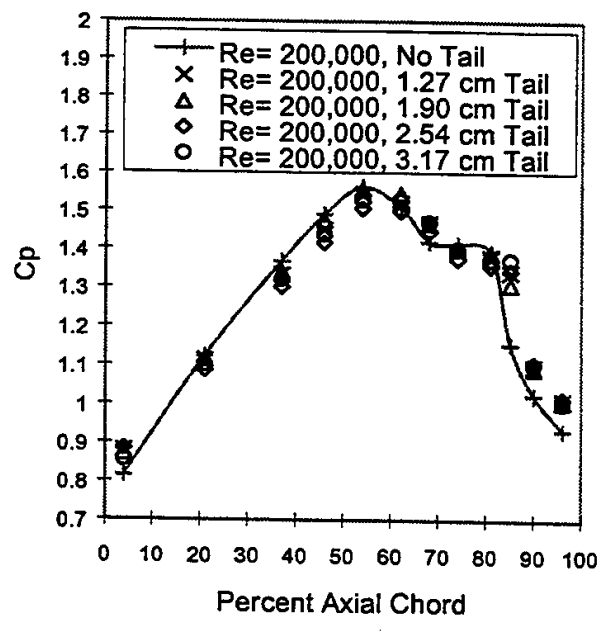

c) $\operatorname{Re}=200,000$

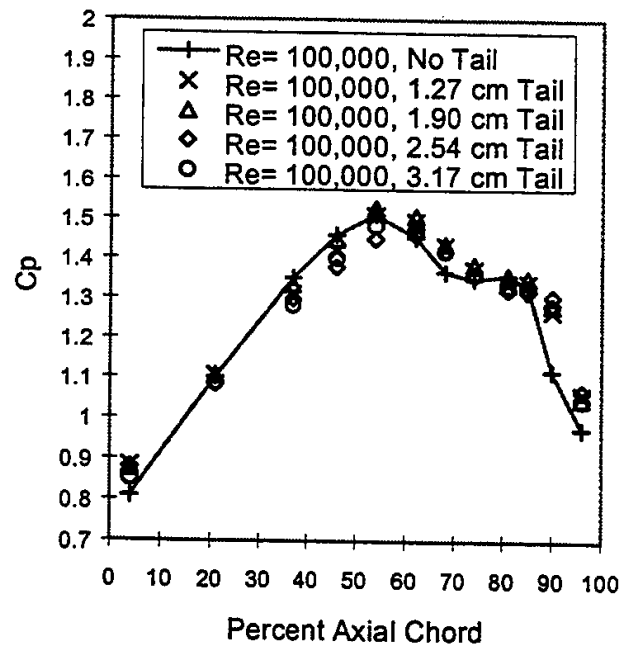

b) $\operatorname{Re}=100,000$

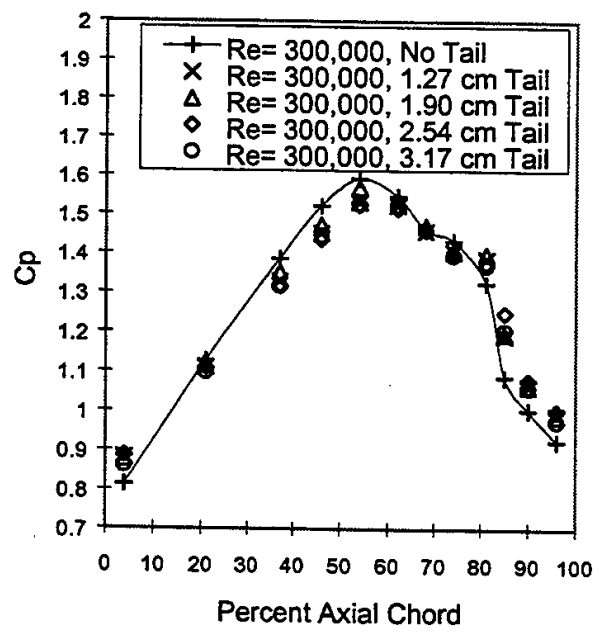

d) $\operatorname{Re}=300,000$

Figure 6. Effect of Variable Axial Chord on the Static Pressure Distribution on the Suction Side for a) $\operatorname{Re}=50,000$, b) $\operatorname{Re}=100,000$, c) $\operatorname{Re}=200,000$, d) $\operatorname{Re}=300,000$ 

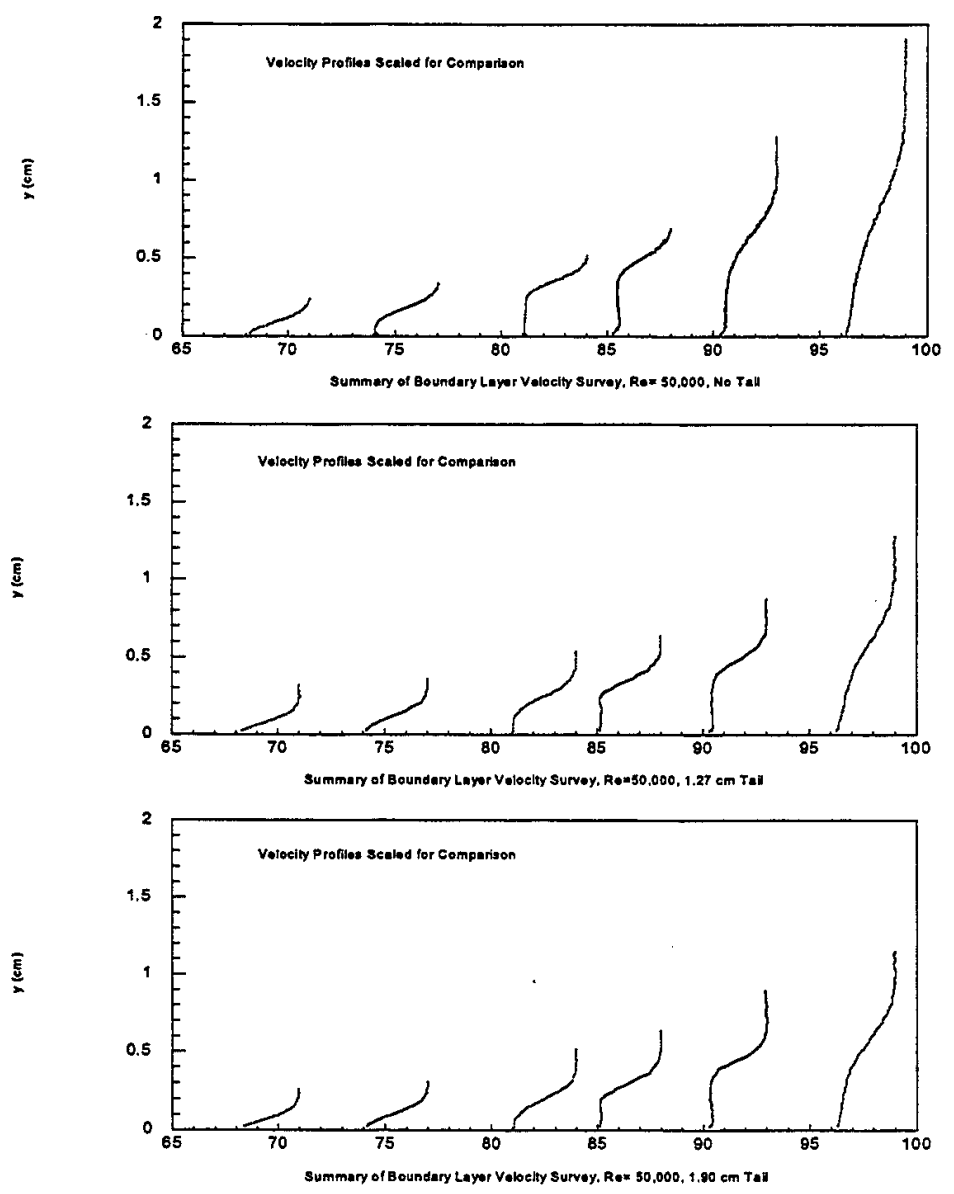

Figure 7. Velocity Distribution at Different Axial Chord Locations along the Blade Suction Side for $\operatorname{Re}=50,000$ 

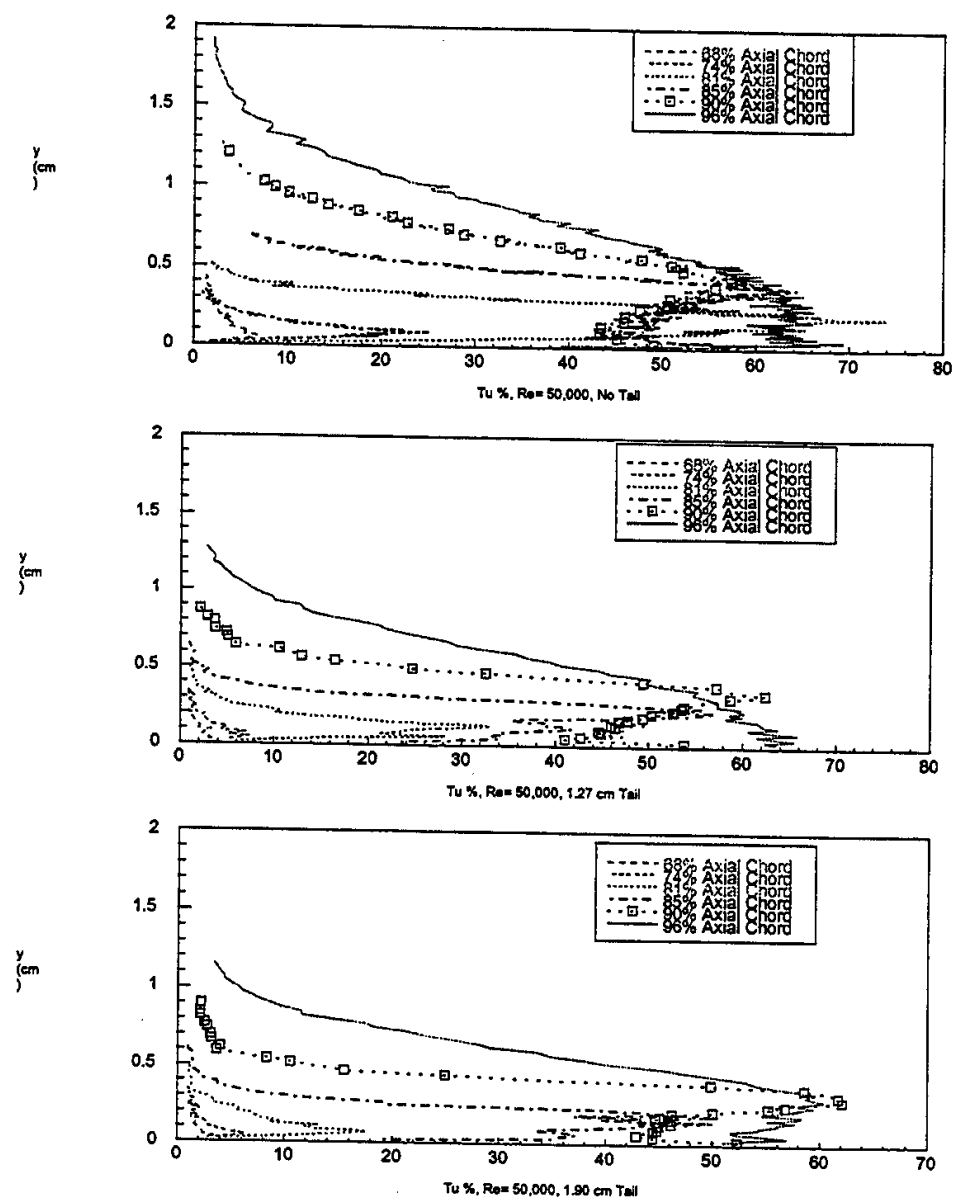

Figure 8. Turbulence Level Distribution at Different Axial Chord Locations along the Blade Suction Side for $\operatorname{Re}=50,000$ 

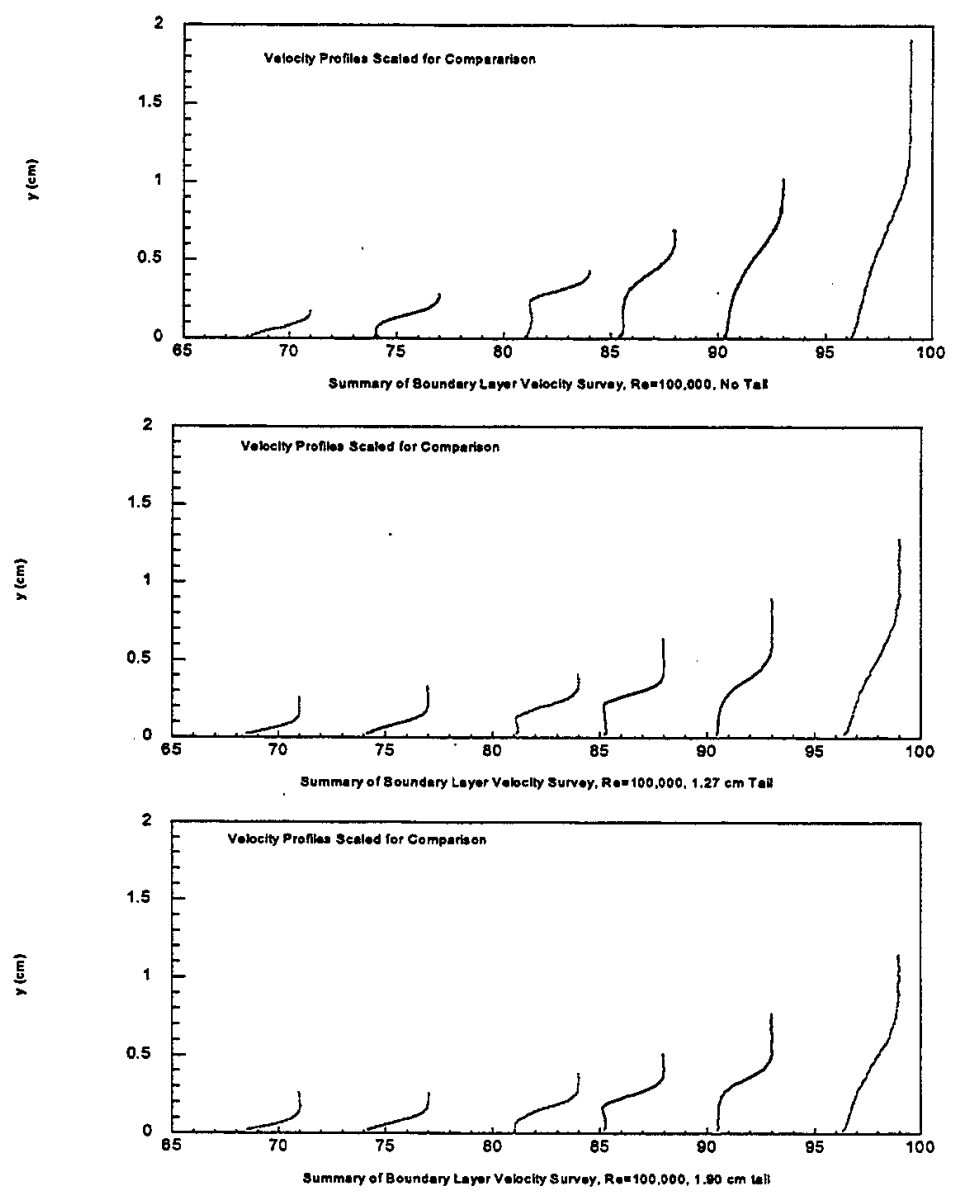

Figure 9. Velocity Distribution at Different Axial Chord Locations along the Blade Suction Side for $\operatorname{Re}=100,000$ 

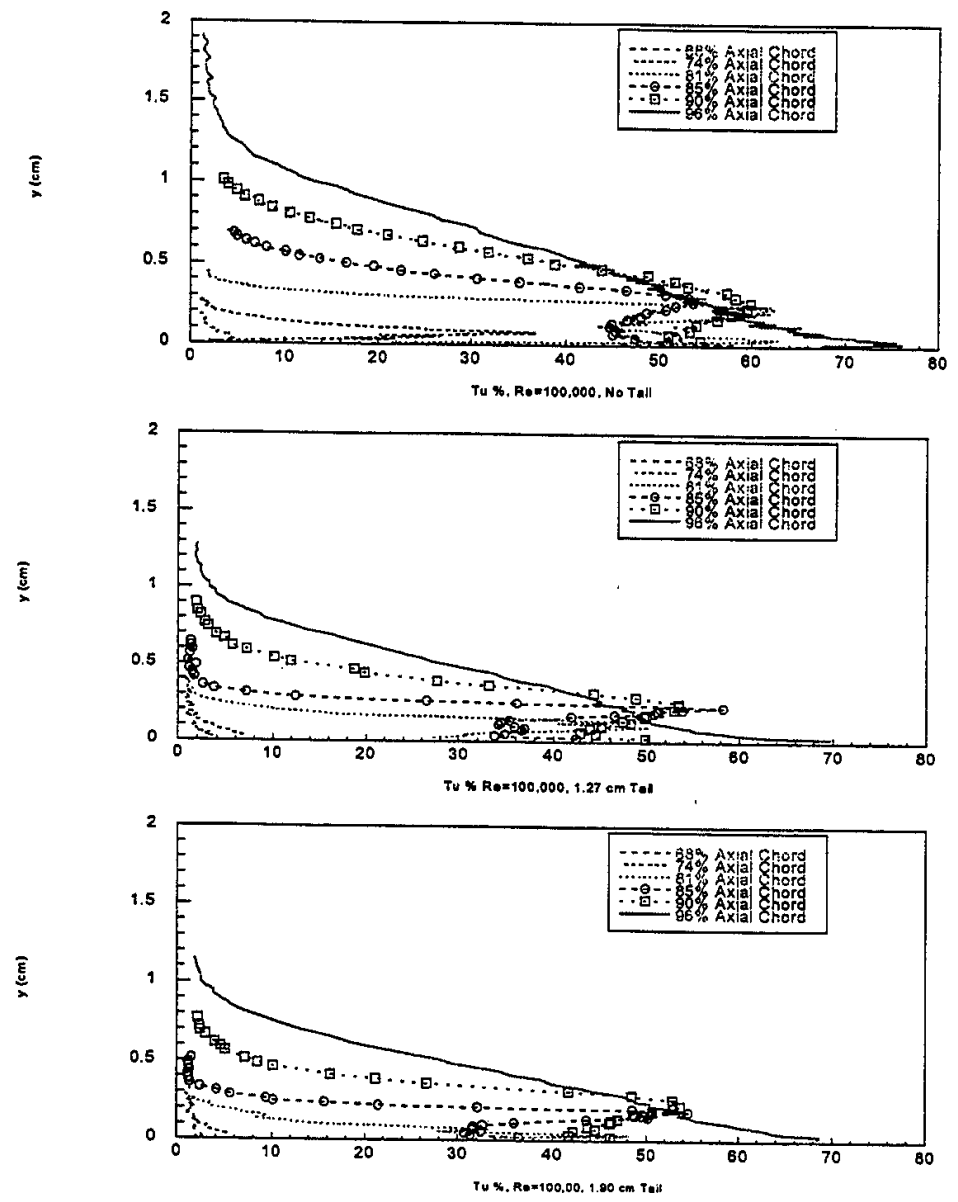

Figure 10. Turbulence Level Distribution at Different Axial Chord Locations along the Blade Suction Side for $\operatorname{Re}=100,000$ 

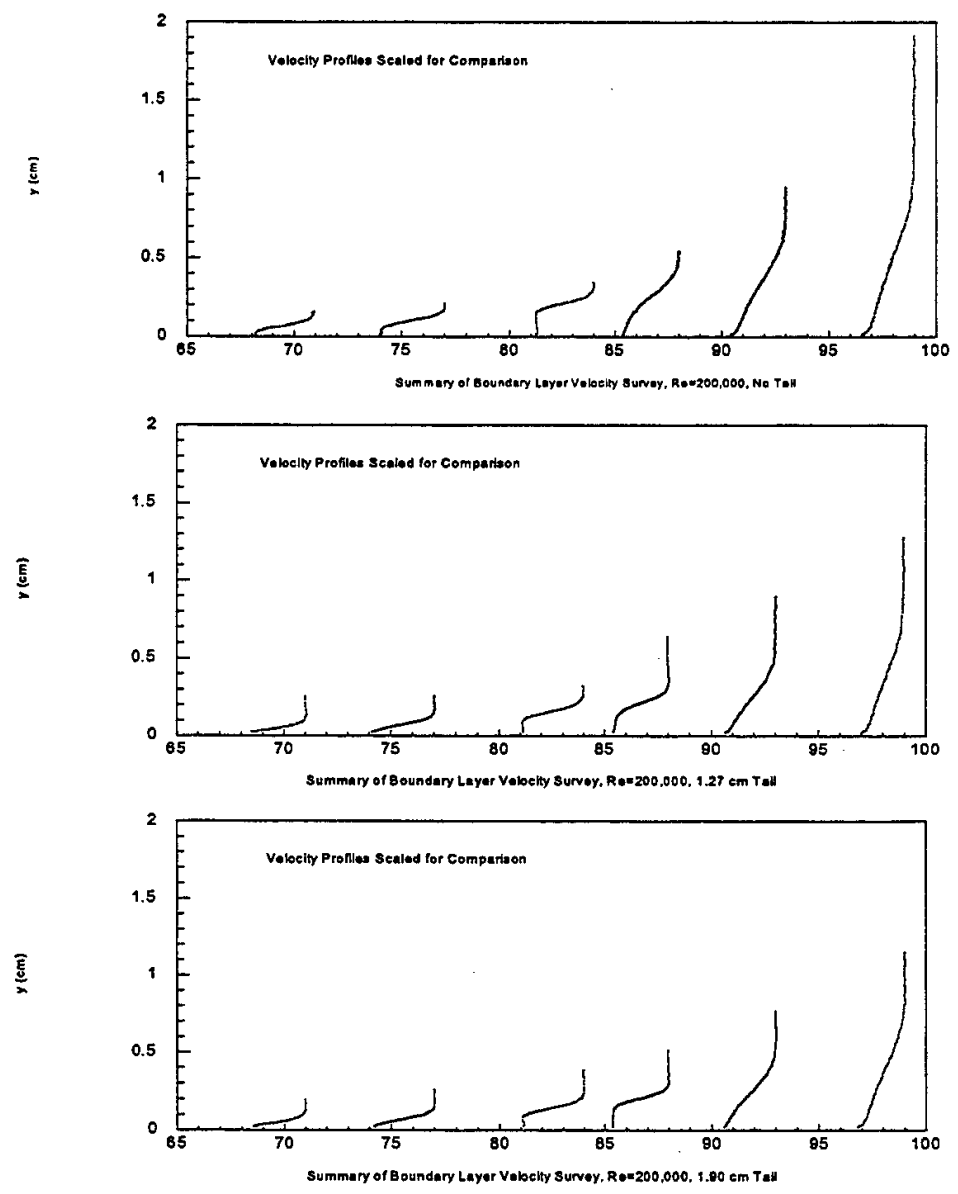

Figure 11. Velocity Distribution at Different Axial Chord Locations along the Blade Suction Side for $\operatorname{Re}=200,000$ 

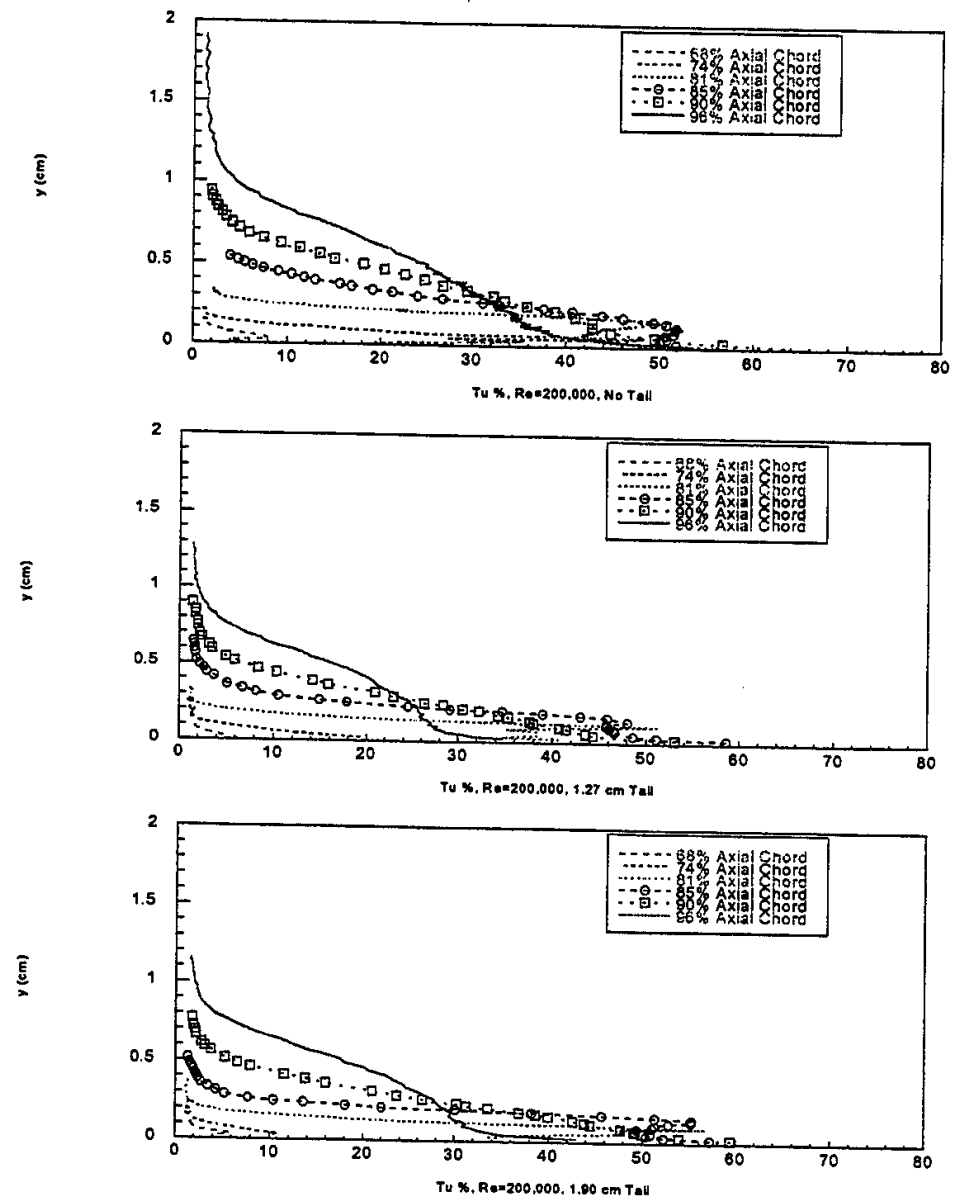

Figure 12. Turbulence Level Distribution at Different Axial Chord Locations along the Blade Suction Side for $\operatorname{Re}=200,000$ 


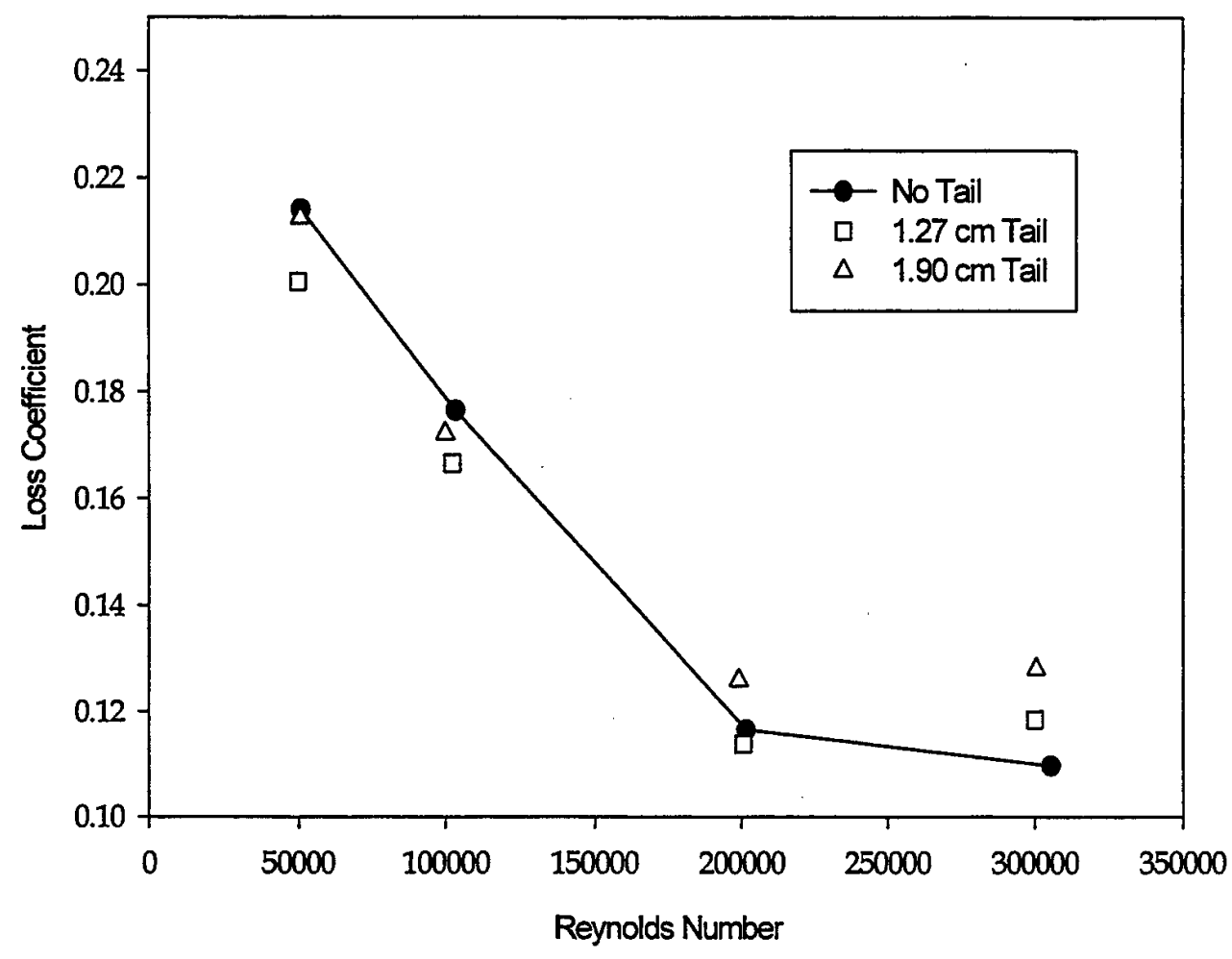

13. Loss Coefficient Variations at Different Reynolds Numbers 